\title{
Heading for the Open Road: Costs and Benefits of Transitions in Scholarly Communications
}

\author{
Michael Jubb \\ Research Information Network, London, UK, \\ Michael.jubb@rin.ac.uk
}

\begin{abstract}
This paper reports on a study — overseen by representatives of the publishing, library and research funder communities in the UK - investigating the drivers, costs and benefits of potential ways to increase access to scholarly journals. It identifies five different but realistic scenarios for moving towards that end over the next five years, including gold and green open access, moves towards national licensing, publisherled delayed open access, and transactional models. It then compares and evaluates the benefits as well as the costs and risks for the UK. The scenarios, the comparisons between them, and the modelling on which they are based, amount to a benefit-cost analysis to help in appraising policy options over the next five years. Our conclusion is that policymakers who are seeking to promote increases in access should encourage the use of existing subject and institutional repositories, but avoid pushing for reductions in embargo periods, which might put at risk the sustainability of the underlying scholarly publishing system. They should also promote and facilitate a transition to gold open access, while seeking to ensure that the average level of charges for publication does not exceed circa $£ 2,000$; that the rate in the UK of open access publication is broadly in step with the rate in the rest of the world; and that total payments to journal publishers from UK universities and their funders do not rise as a consequence.
\end{abstract}

Key Words: scholarly communications; publishing; open access; economics; modelling

\section{Introduction}

Before the last two or three years, there had been few attempts to delineate the most basic features of the economics of the scholarly communications 
landscape. Debates on future developments in general, and on open access in particular, were thus almost entirely unsupported by economic evidence or analysis. That began to change in 2008 and 2009 when the Research Information Network (RIN) published a report ${ }^{1}$, based on work done by Cambridge Economic Policy Associates (CEPA), which analysed the activities, costs and funding flows in the scholarly communications system. And then the UK Joint Information Systems Committee (JISC) published a report commissioned from a consortium of researchers - led by John Houghton - at Victoria University in Australia and Loughborough University in the UK. ${ }^{2}$

These and other studies have their limitations, not least in their focus on static comparisons between the world as it is now and a wholly - or nearly wholly - open access world. Nevertheless, it does seem clear that if we could - as it were by magic or decree - move to such a world next week, we could achieve significant savings and increases in both efficiency and effectiveness. But two key questions have remained unresolved. First, how might we organise a transition to an open access regime, when the transition itself would bring additional costs, when in many leading research nations university and research budgets are under severe pressure, and when the costs and benefits will vary in different parts of the scholarly community and in different parts of the world? Second, how might an open access regime be organised so that it is supported by flows of funding sufficient to render sustainable the quality assurance, navigation, preservation and other services that underpin the research endeavour?

In an attempt to begin to address these kinds of questions, the RIN engaged in 2009 in lengthy discussions with representatives from a range of organisations in the UK with interests in publishing, libraries and research funding. The organisations involved in the discussions - the Association of Learned and Professional Society Publishers (ALPSP), the Publishers Association (PA), the Publishing Research Consortium (PRC) and the International Association of Scientific, Technical and Medical Publishers (STM) from the publishing side; the British Library, the Joint Information Systems Committee (JISC), Research Libraries UK (RLUK), the Society of College, National and University Libraries (SCONUL) and SPARC Europe from the library side; and Research Councils UK (RCUK), the Wellcome Trust, and Universities UK (UUK) from the funder and institutional sides - all share an ambition for significant improvements to access. But they have not achieved a consensus on 
how to reach that goal. They nevertheless agreed to work together on a series of projects with the aim of

'building a common understanding of the incentives, constraints, costs and benefits associated with improving access to research outputs; and of promoting the continuing development of a scholarly communications system that is sustainable, efficient and effective in meeting the needs and aspirations of the research community in the UK and globally.'

The most ambitious of the three studies commissioned so far examines the dynamics of seeking to improve access to journal articles in five different ways over a five-year period; and the costs, benefits, opportunities and risks that each entails. ${ }^{3}$ It involves an examination of the drivers required for change, the costs involved in making the transitions, and the benefits that would be likely to accrue. The study was undertaken by CEPA LLP (Joel Cook, Daniel Hulls and David Jones) and Mark Ware Consulting Ltd (Mark Ware). Their work was overseen by a steering committee comprising representatives of the five organisations directly involved in commissioning and funding the study. ${ }^{4}$ The study started in April 2010, and the report was published in April 2011.

The analysis and the modelling cannot, of course, claim to have captured all the complexities of the scholarly communications system. Moreover, the study is essentially an exercise in comparison, and therefore places more weight on the comparisons between the scenarios and the sensitivities associated with them than on the absolute values that result from the modelling. Nevertheless, the findings and conclusions are well-founded in those terms as a basis for further work and policy discussion.

\section{Scenarios}

At the heart of the study is an attempt to define and then compare five plausible but challenging scenarios that increase access to scholarly articles over the next five years. ${ }^{6}$ With the exception of the 'transactional' scenario (essentially an extension of current pay-per-view (PPV) arrangements), 'access' is taken to mean that user groups are able to read, download and print a scholarly article without additional cash payment by them or their institution. The comparison and the associated modelling can best be described as a UK costbenefit analysis, which builds on previous work by RIN, JISC and others. 
A key first stage of the study was therefore to define, after an extensive literature review and with the help of interviews and a workshop involving a range of stakeholders, five scenarios to be achieved by 2015. They are summarised in Table 1.

Table 1: Summary of the five scenarios for 2015

\begin{tabular}{|l|l|}
\hline Scenario & Summary Description \\
\hline Areen Open & $\begin{array}{l}\text { Increased rates of deposit of accepted manuscripts into institutional } \\
\text { and discipline-based repositories driven by enforcement of mandates } \\
\text { by funders globally (40-60\% deposit rates depending on discipline) and } \\
\text { by UK, US and European universities and research institutions (15-30\% } \\
\text { deposit rates). }\end{array}$ \\
\hline Delayed Access & $\begin{array}{l}\text { A significant increase - to 40\% - in the number of publishers } \\
\text { providing free access through their platforms to the version of } \\
\text { record for 65\% of the articles they publish, following an embargo } \\
\text { period. Embargoes are set in relation to the readership 'half-life' and } \\
\text { are assumed to be 12 months (biomedical); } 24 \text { months (science \& } \\
\text { technology); 36 months (arts \& humanities). }\end{array}$ \\
\hline $\begin{array}{l}\text { Gold Open } \\
\text { Access }\end{array}$ & $\begin{array}{l}\text { Increased proportion of articles published with author-side payments } \\
\text { leading to immediate access to the version of record. Applicable } \\
\text { globally and to all disciplines as follows: biomedical (40\%); science \& } \\
\text { technology (15\%); arts \& humanities (5\%). } \\
\text { We consider two variants of this scenario, to show the impact of a } \\
\text { higher or lower level of article processing charges (APCs). }\end{array}$ \\
\hline Licence Extension & $\begin{array}{l}\text { Increased access to the version of record achieved through national } \\
\text { licence extensions to (i) all Higher Education Institutions (HEIs), with } \\
\text { 50\% of larger publishers agreeing licence extension for the higher } \\
\text { education sector as a whole, covering 75\% of articles; and (ii) the } \\
\text { National Health Service (NHS), with 30\% of relevant (i.e. primarily } \\
\text { biomedical) publishers participating, covering 55\% of relevant articles. }\end{array}$ \\
$\begin{array}{l}\text { Increased access focused on targeted user groups (e.g. small } \\
\text { and medium enterprises (SMEs), independent researchers and } \\
\text { professionals). Access to the version of record at the point of } \\
\text { publication. Primary access expected to be via aggregating sites. A pay- } \\
\text { per-view (PPV) price of \$10 is considered. }\end{array}$ \\
\hline Transactional
\end{tabular}

\section{Modelling and Analysis}

For each scenario we analysed the drivers and transition steps (the activities likely to be required for the scenario to be realised by 2015); modelled steady state and transition costs; quantified the changes in the access; and estimated 
the wider economic benefits. ${ }^{7}$ We then draw comparisons and make judgements about the relative cost-effectiveness of different approaches to increasing access, and draw some policy conclusions.

It is important to note that each of the scenarios is compared to a baseline for 2015 rather than 2010, in order to take account separately of anticipated system-wide changes between 2010 and 2015 that would affect all scenarios. The 2015 baseline is what might be thought of, therefore, as a 'policy neutral' position against which we compare each of the access policy scenarios. In addition, for each scenario we explored key sensitivities. For example, for the Green and Gold scenarios we considered how sensitive our results were to relaxing the assumption that the UK and the rest of the world move in step in terms of the levels of deposit rates (for Green) and author-side payment (for Gold). Similarly, we have tested the impact of changing embargo periods (for Green and Delayed), the discount on the version of record (for Green), and the premium paid for licence extensions by + or $-50 \%$; and the transactional price by -50 to $90 \%$.

Throughout the analysis we refer to two measures of the change in access. The first is a standardised unit of access (SUoA), designed as a common currency of access with discounts to take account of embargo period, version and functionality. For the Gold scenario, we assume that the user is able extensively to re-use the article (e.g. under a Creative Commons licence or equivalent) but not necessarily to re-use it for commercial purposes (Open Access [OA] publishers currently vary on this latter point). For the other scenarios we assume that such broad re-use rights are not generally included. In practice there will be a mosaic of different permissions applying to articles from different publishers. Although we acknowledge the potential value in such re-use, it is difficult to model, for two reasons: first, the lack of uniformity; and second, that the more substantial value is likely to be a non-linear network benefit which derives from the ability to re-use a large corpus of work (e.g. in text- or data-mining) rather than being attributable to an individual article. For these reasons such differences in permissions and re-use rights are not explicitly valued in the benefit-cost analysis.

The second measure seeks to adjust the standardised unit of access to take account of existing levels of access. For any given researcher the assumption is that there will come a point when access to additional articles will have 
reduced value. For example, imagine a researcher with access to a wellstocked library covering all core journals and many of the journals in peripheral or related fields. It is reasonable to expect that as more journals are added to the library's collection, on average the proportion of high-quality articles relevant to the researcher in each additional journal will decline. For any given increase in overall access, therefore, the increase in useful access will depend on user groups' existing level of access. This is the familiar economic concept of diminishing marginal returns (DMR).

The model estimates the size of this potential effect by using data from surveys that asked researchers to describe their ease of access to research articles to calibrate a DMR curve. By definition, the changes in useful access estimated by the model are less than the standardised units of access. We note that there are arguments to suggest that DMR may not always operate in this market or indeed in others. For this reason, we use the useful access measure to calculate the lower bound of our benefit estimates, and focus more generally on the mid-point estimates.

\section{Changes in Access and Costs to the UK}

In Sections 4-5, we do not compare the results of the transactional scenario with the other scenarios, because it is not directly comparable in terms of the access changes, costs and benefits. However, we note that a transactional route could be complementary to a licence extension in particular, and that, on the other hand, a significant increase in either green or gold open access would reduce the potential market for PPV.

\subsection{Increases in Access}

Figure 1 shows the estimated increases in the two measures of access in each scenario, as compared to the 2015 baseline. These increases reflect the assumptions that define the scenarios (in Table 1) as well as our modelling assumptions. With the exception of NHS Licensing, the increases are of a similar order of magnitude in each case. It is important to note, however, that the increases are unevenly distributed: with the Green, Gold and Delayed scenarios in particular, the user groups with lower initial levels of access - including SMEs — see the largest proportionate increases. 
Fig. 1: Changes in SUoA and useful access compared to the 2015 baseline.

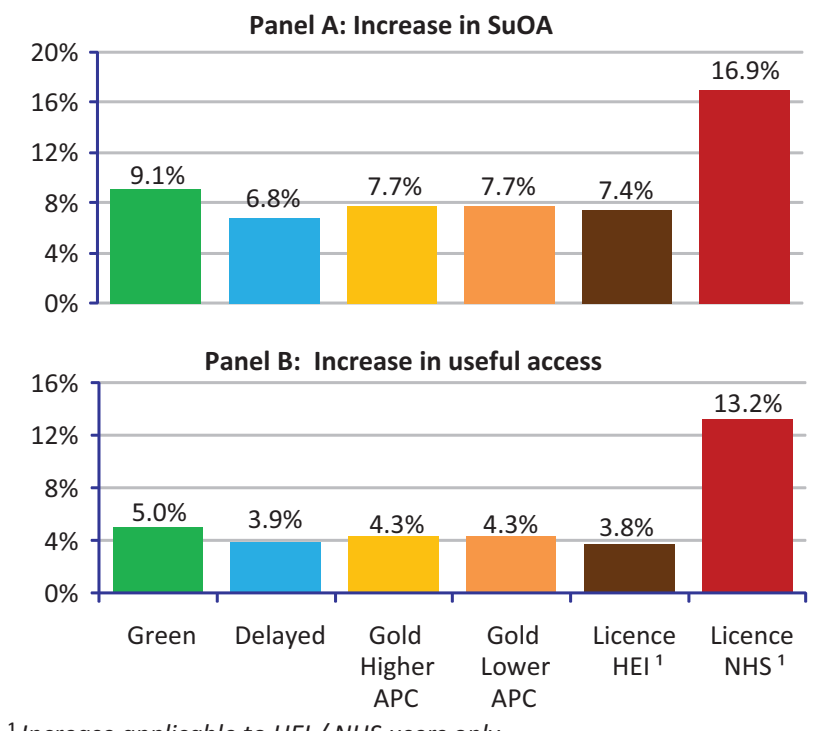

${ }^{1}$ Increase applicable to HEI / NHS users only

\subsection{Costs to the UK}

Each of the scenarios involves some element of initial expenditure in order to support transition. Figure 2 shows the estimated 'one-off' transaction costs associated with the transition (Panel A) and continuing annual costs ${ }^{8}$ (Panel B) to the UK.

The level, composition and profile of ongoing annual net costs or savings vary significantly between the scenarios, and also in their distribution across user groups and institutions.

The one-off and continuing costs associated with the Green scenario are relatively low compared with most of the other scenarios. But this cost comparison may be misleading, since for Green it covers only the additional cost as compared to the 2015 baseline, within which most of the costs of establishing repositories are sunk. If the sunken costs were to be included in the comparison, Green would become the most expensive scenario to the UK, with additional net annual costs and one-off costs both in excess of $\mathrm{M} £ 10$. 
Fig. 2: Comparison of UK net annual costs.
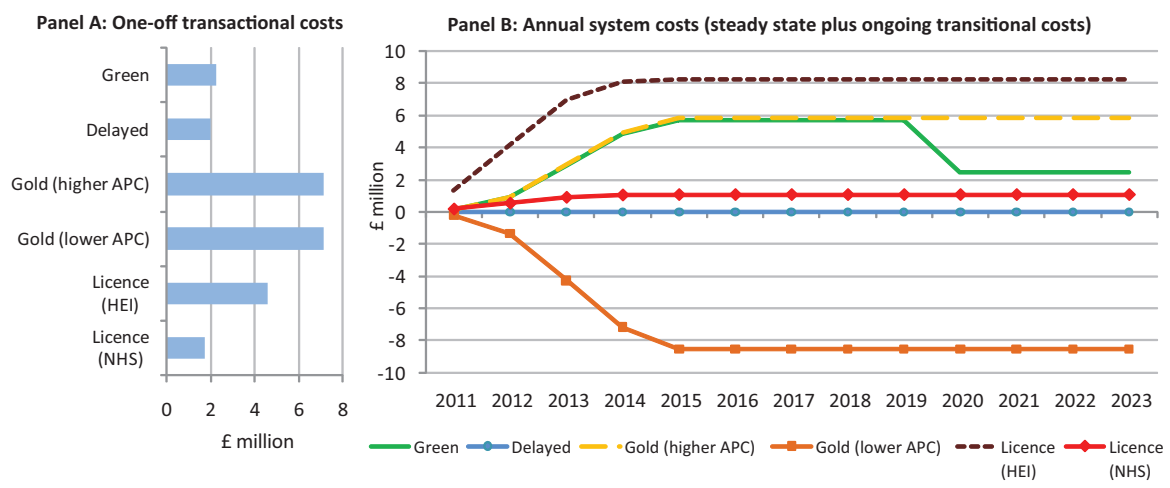

The Delayed scenario imposes no ongoing costs, and has low one-off transaction costs, incurred by publishers.

The Gold scenario has the highest expected one-off transition costs, associated with funders and universities developing the business case to meet author processing charges (APCs); developing and adopting central funds; developing and communicating models and mechanisms to process APCs; developing publisher billing systems to deal with APCs; and negotiations between publishers, universities and consortia to establish publishing deals.

Gold is, however, the only scenario that could in principle reduce the net annual costs for the UK, and in particular, for UK universities. But it would do so only if the weighted average level of APCs was low enough so that, in a steady state, the increased costs of paying them was outweighed by a fall in subscription payments (as increasing numbers of articles became available as gold OA). Thus

- if average APCs were set at a level equal to our estimate of the current global average cost per article $(£ 2,634)$, UK universities' annual cash costs would rise significantly.

- if average APCs were set at about $£ 1,457$ (or $\$ 2,185$ - the estimate by Outsell of the 2009 weighted average for actual APCs charged) ${ }^{9}$ then UK universities would benefit from substantial annual net savings 
that we estimate at $\mathrm{M} £ 2.8$ (or M£3.0 including non-cash savings) at the level of uptake we have modelled.

The continuing costs associated with the Licence Extension scenario depend largely on the assumed licence premium. The one-off costs vary between the HEI and NHS licence scenarios, largely reflecting expected negotiation costs. But both the continuing and the one-off costs appear to fall somewhere between Green and Gold.

\section{Cost-effectiveness and Benefits}

\subsection{Cost-effectiveness of Increasing Access}

In order to compare cost-effectiveness, Figure 3 shows the net cost to the UK per additional SUoA for each scenario. This cost-effectiveness measure is calculated by dividing total average annual net costs by the absolute increase in SUoAs that are expected to result by 2015 .

Fig. 3: Comparison of the net cost to the UK per additional SUoA.

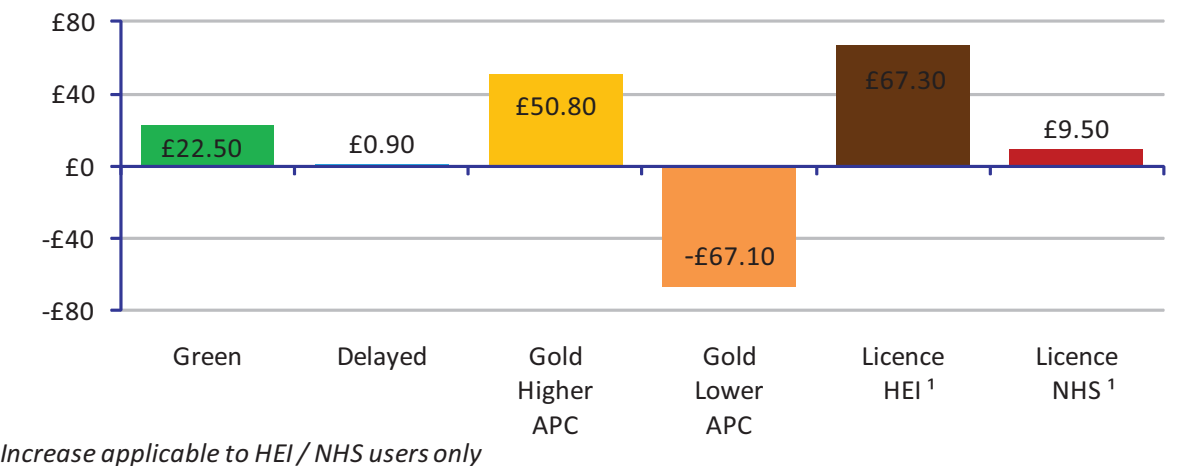

With the exception of the NHS licensing scenario (which has a significantly higher increase in access) the relative position of the scenarios broadly reflects the differences in net costs shown in Figure 2: 
- in the Green scenario, the cost per additional SUoA depends on whether or not the costs of establishing repositories are taken into account. Ignoring these sunk costs suggests costs per SUoA broadly in the middle of the range of other scenarios. Taking account of sunken costs would push the cost per SUoA towards the upper end of the range.

- the Delayed scenario comes very close to being a cost-free route to increased access, in terms of both upfront and ongoing costs.

- the cost effectiveness of the Gold scenario varies dramatically depending on the assumed level of the APC. There is thus a net saving (shown as a negative cost in the figure) to the UK per additional SUoA if APCs are kept low, but a high net cost if they reflect our estimates of the current costs of publishing each article.

- the cost per SUoA in the Licence Extension scenario for the NHS is low, although it provides an increase in access only to a particular population, unlike the other scenarios which provide open access. The Licence Extension scenario for HEIs appears to be a relatively expensive approach to increasing access.

\subsection{Distribution and Profile of Costs}

Figure 4 shows the profile of the steady state, ongoing transition and oneoff costs for academic institutions (Panel A) and other contributors (Panel B). In all scenarios (except Delayed and NHS Licence extension) most of the increases in cost are incurred by academic institutions.

This distributional impact is particularly acute in the Gold higher APC scenario, where academic institutions experience significant increases in the costs they face while other contributors see reductions. This is, however, a function of the assumed cost of bringing an article to publication (met by the APC plus funding from advertising, etc). ${ }^{10}$ The Gold lower APC scenario would lead to cash savings by institutions. It is the only scenario that could achieve that result.

Unlike Gold the Green scenario does not offer a route to cost savings for academic institutions, but instead involves increased annual costs, except in circumstances that give rise to other concerns as to sustainability. Although cheaper than the Gold at the higher APC level, Green is significantly more 
expensive $^{11}$ for academic institutions than Gold at the lower APC level, although the two are probably not mutually exclusive.

Fig. 4: Profile of total steady state, ongoing transition and one-off costs.
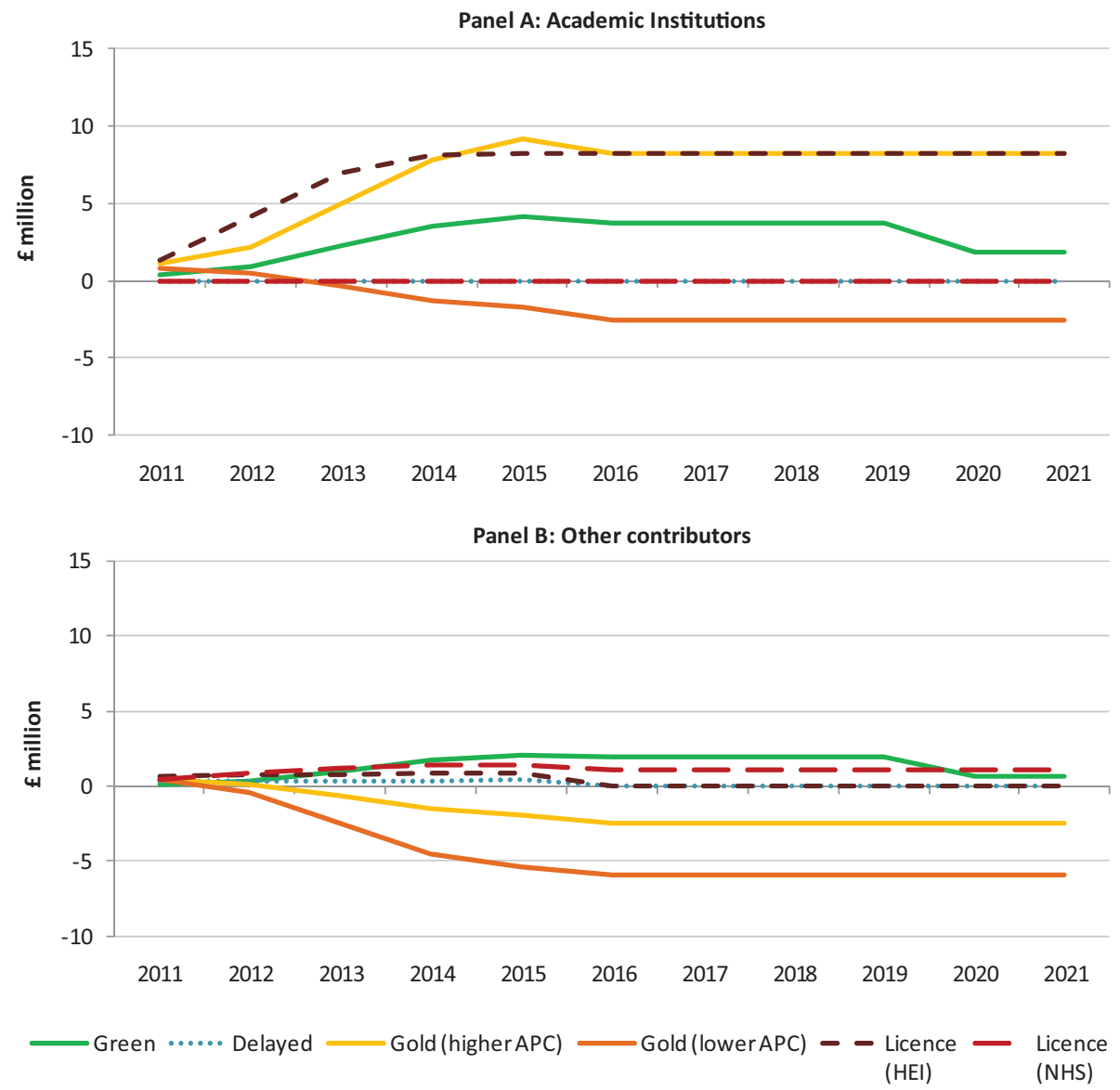

\subsection{Benefits and Cost-effectiveness}

The benefits that arise from each scenario reflect the increase in access provided to each user group: universities, Government, NHS, corporations and SMEs. The increases in our two access measures were used to estimate a 
range for potential UK economy-wide benefits using the 'Solow-Swan' economic growth model. ${ }^{12}$

We have compared these estimates of benefits in each scenario with their respective costs in order to calculate benefit-cost ratios (BCRs). The costs and benefits were calculated as net present values (NPVs), which are the values of the net costs or benefits over twenty years converted into 2015 values via a discount rate. Figure 4 summarises this analysis, which provides an indication of the potential economic case for each scenario, and an alternative metric to compare cost-effectiveness. Given the relationship between increased access and economic benefits, the relativities are similar to those described above in Figure 3; and for reasons explained in the report, we have greater confidence in the comparisons between scenarios than in the absolute values.

In the tinted bars on the chart (Figure 5), the lower bound reflects the benefit estimates derived from using the measure of access that takes account of potential diminishing marginal returns ('useful' access); the upper bound reflects access without this adjustment (SUoA). The diamond denotes the mid-point of the range. The vertical lines represent the ranges covered by the various sensitivity analyses that we have conducted, details of which are provided in the report.

Fig. 5: Benefit-cost ratios.

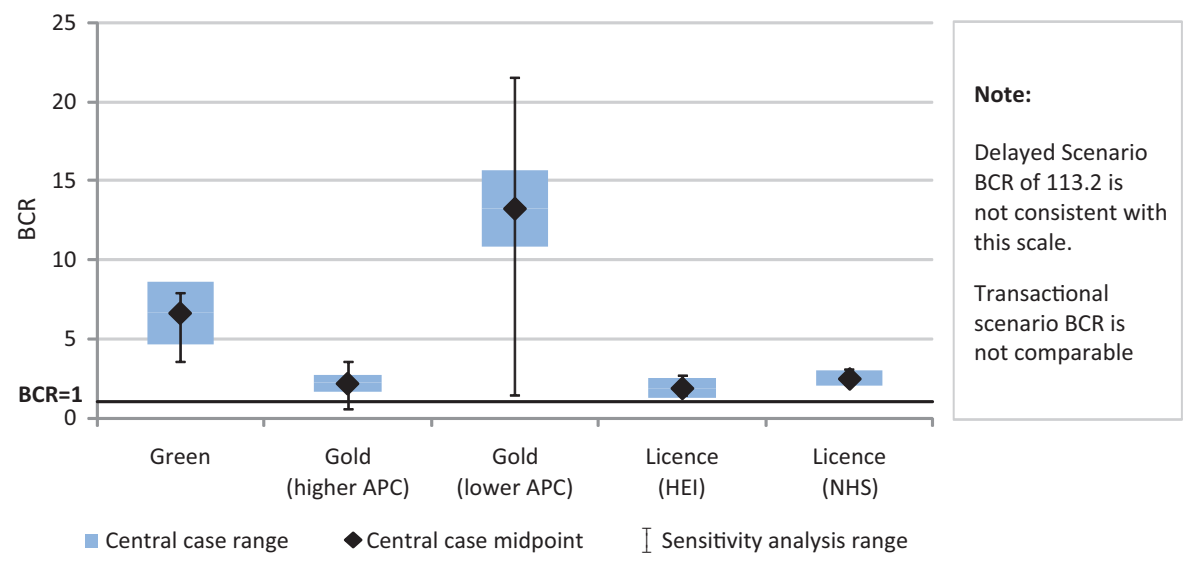


The modelling confirms what one might intuitively expect, that the Green scenario would provide a cost-effective route to improving access, with relatively high BCRs attributed to our central case in which much of the costs are treated as sunk. These BCRs and the overall economic case are relatively robust to our sensitivity analysis (illustrated by the line). However, as discussed below, the Green scenario may carry a relatively higher risk than the other scenarios given its potential to undermine the business model on which it relies; and that risk is not captured in the sensitivity analysis.

The midpoint BCR for the higher APC Gold scenario is relatively low. However, with lower APCs the BCR midpoint is considerably higher. This demonstrates how the $\mathrm{BCR}$ for the Gold scenario are probably the most sensitive to changes in key assumptions. This is particularly true of the assumption that the UK moves in line with the rest of the world in terms of take-up of Gold OA - which provides the lower end of the sensitivity range - and is less than 1 in the higher APC case. ${ }^{13}$

As with Gold, the cost-effectiveness of the Licence Extension scenario depends directly on the assumed licence premium that would be charged by publishers. At the assumed level of premium both HEI (7.5\%) and NHS (15\%) licence extensions have the potential to offer a net benefit to the economy, with the NHS licence extension appearing to have a marginally better BCR.

\section{The Transactional Scenario}

A reduction in price of pay-per-view (PPV) articles could increase access to users who would not otherwise decide to purchase an article. The increase in access depends on publishers' willingness to reduce prices. For publishers to be willing to do so, two conditions would have to be met: (i) that the price reduction would lead to an increase in volume (and therefore revenue) that outweighed the loss of revenue from the reduced price for articles previously sold; ${ }^{14}$ and (ii) that the price reduction would not cannibalise revenue from other segments of the publishers' market, in particular subscriptions.

We do not have evidence on either of these, but we have developed an illustrative scenario where both conditions hold, with a price reduction from $\$ 30$ to $\$ 10$ per article. ${ }^{15}$ This leads to the number of articles purchased in the UK increasing from 58,000 to 300,000 . We assume that most would be pur- 
chased by corporations and SMEs; but other groups would also increase their purchases.

The costs to users of purchasing the additional articles would be circa $\mathrm{M} £ 1.3$. $^{16}$ Of course the additional costs to users represent additional revenue to publishers. There are no net transition costs in this scenario, since setup costs associated with a new aggregating site(s) or better/easier payment systems are assumed to be captured in the average price per article. BCRs cannot be calculated in the same way as for the other scenarios, and we have focused instead on the change in consumer surplus (the difference between what a consumer actually pays and what they would be willing to pay) that results from the reduction in price. The BCR depends on the assumed elasticity of demand and the size of the price reduction. We have calculated it as 2.0 in the central case.

The scale of the change we have modelled is small. But the key question is why we have not seen publishers reducing PPV prices. We presume in short that it is because either they do not believe that the conditions relating to demand and the cannibalisation of other revenue are realistic, or they think the additional revenue is too low to justify the effort. It is possible that a third party, such as Deep Dyve, prepared to invest in aggregating content and in improved user services, may be a route to increased usage. But there is no sign as yet that the impact on the total system will be other than small.

\section{Risks}

The past five years have brought rapid change in the scholarly communications system as a whole: new technologies and services have brought changes in the roles, behaviours and attitudes of all the key groups of players in the system - universities, funders, libraries, publishers and researchers themselves. Rapid change brings many kinds of risks, and we cannot capture all of them in our modelling. We have, however, considered three groups of risks in relation to each scenario over the next five years: potential impact on the overall funding or viability of the scholarly publishing system; risks to the transition process; and risks to achieving the calculated BCRs. Figure 5 provides a summary assessment of those risks. We must stress that this reflects a judgement of the relative riskiness of the scenarios. It is not an assessment (quantified or otherwise) of absolute levels of risk: 
- The Green scenario involves a relatively high risk to the scholarly publishing system as a whole, since it could give rise to significant levels of subscription cancellations, rendering some journals and publishers unviable. However, the risks to the transition and BCR are not thought to be as great as for other scenarios.

- The Delayed scenario involves some risk of subscription cancellations, but less than Green since publishers would have more control. Costs are very low, so the transition and $B C R$ risks are also lower than other scenarios.

- The Gold scenario presents a relatively low risk to the scholarly publishing system as a whole, since it offers a viable alternative business model. There are, however, slightly greater risks with respect to the transition (for funders, universities and publishers) and relatively high risks associated with achieving the BCR.

- The Licensing extension scenario has in our judgement higher risks related to transition, but relatively low risk in the other categories.

- The Transactional scenario's greatest risk is to the system as a whole from the potential cannibalisation of subscriptions, but given publisher autonomy, our judgement is that risk is not as high as the Green scenario. Transition and BCR risks are both low.

Fig. 6: Relative risks of scenarios.

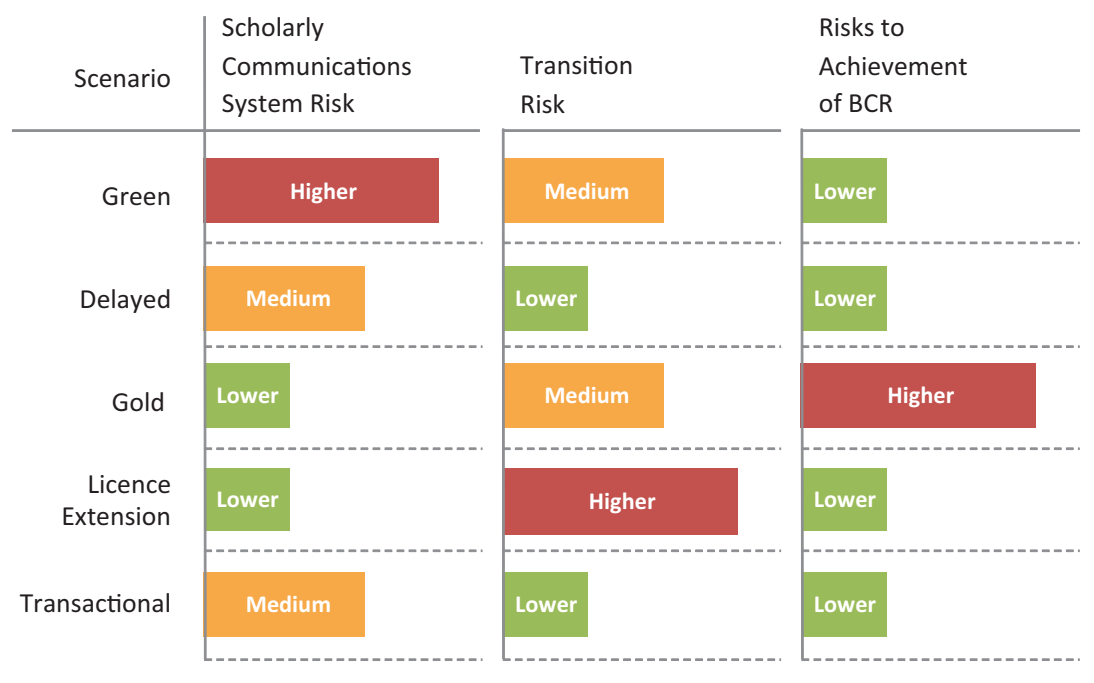




\section{Findings in Summary}

This report appears at a time of growing financial constraint in the UK academic system. Against this background all cost items, large and small, will come under increased scrutiny. In this context we start by noting that all the scenarios involve some additional cost at some point, although the amounts and timing vary.

\subsection{Delayed}

The Delayed scenario comes close to the desirable outcome of a cost-free route to increased access; and the transition costs would be borne by publishers rather than academic institutions, which might be seen as an advantage from a public policy perspective. The BCR suggests that this scenario clearly offers the most cost-effective way to improve access, largely as a result of the lowest costs.

The scenario is not, however, very amenable to policy intervention, since it depends on individual publishers' decisions to adopt it or otherwise. Some have suggested that pressing harder for Green OA might trigger an increase in delayed access as a response, but there is little evidence to support this.

Our view is that delayed access is unlikely to expand substantially, since there is too little incentive for publishers who have not already for their own reasons chosen to adopt it. It also seems unlikely that academic institutions or funders will prioritise this option over Green or Gold OA, because of its disadvantages (longer embargoes; lack of deposit in open repositories). Publishers could, however, increase the access value if they made the postembargo articles truly open access (e.g. with a Creative Commons licence) rather than just freely available.

\subsection{Gold}

Gold is the only scenario that could in principle reduce the annual costs for academic institutions, so long as the average level of APCs were to be below circa $£ 2,000$ (the level at which the net cost to UK universities would be zero assuming commensurate reductions in subscriptions payments). At such a level the economic case for the Gold scenario would be especially strong, with high BCRs and with the clear advantage of providing a sustainable funding model. 
There are, of course, significant uncertainties about how Gold OA publishing — and the level of APCs - will evolve, and about the impact on traditional publishers' business models. It is likely to be a challenge for many publishers to shift a significant part of their existing portfolios to a lower-cost Gold model. Nonetheless, a number of publishers, including Nature Publishing Group, Sage and the British Medical Journal, are now launching open access journals with APCs in the range $\$ 1,350-\$ 1,700$.

It may be easier for new entrants to operate at this level, because they can design low-cost operations from scratch and they do not need to worry about cannibalising existing, potentially more profitable revenue streams; or because they focus on journal models with light peer review and lower rejection rates, and hence lower editorial costs. It is also possible that publishers may set prices artificially low as a market entry strategy, or that APCs may rise as Gold OA publishers mature and increase the proportion of 'higher-rejection rate' journals in their portfolios. But it is important to note that the weighted averages we used in our calculations include some high and medium level APC journals, which suggests APCs at an average level below $£ 2,000$ could be feasible as Gold expands.

In any large-scale transition to Gold, however, a number of important issues would have to be addressed:

- There are significant one-off costs to create the necessary infrastructure and systems. Practical payment issues like handling post-grant publication, multi-authorship and authors who move from one university to another are yet to be fully resolved, and where policies have been drawn up, researchers are far from familiar with them. Payment for non-grant-funded authors requires funding from universities, and the funding, policies and communication for this has barely started (only a handful of UK universities have established OA funds). These costs are included in the benefit-cost modelling, although much of universities' share (roughly half of the total) would be management and staff time.

- There are also lags and distributional effects that mean that ongoing net costs would rise before later falling, as a result of the need to pay APCs while retaining existing subscriptions. This 'hump' in costs (only partly reflected in our model, which does not include lagging) is likely to be one of the biggest obstacles to the growth of Gold. 
The hybrid OA model could have a role in mitigating this short-term cost hump. But it has to date seen only low uptake, and has incurred some suspicion, partly because of concerns of potential 'double dipping' and partly due to the pricing. The variant of the hybrid model in which a consortium deal provides a bundle of licensed access and APCs for a single agreed price may have a role here, so long as the model can be given sufficient transparency for institutions to have confidence in it, and if the APCs are low enough.

- The expansion of Gold would also have differential impacts on universities, in effect redistributing the share of total publishing/distribution costs from more teaching-oriented institutions to the researchintensive ones. This should not cause major difficulties, however, so long as charges are met by the Research Councils and other major research funders who provide project grants, rather than out of the block grants supplied by the Funding Councils. It is also likely to be much less of an issue if the net cost falls for everybody, as we see in the steady state when average APCs are lower than circa $£ 2,000$.

More generally, the importance of the level of APCs in determining the case for Gold raises the question of whether funders' or universities' policy should specify a maximum reimbursable APC, in order to promote a lower overall average. On balance we think that this is not likely to be desirable, for several reasons: unlike subscriptions, the market for APCs is likely to involve some competition on price; the evidence currently suggests that it is unnecessary; and a cap could discourage high quality journals with inherently high editorial costs from entering the Gold arena.

\subsection{Green}

Our analysis confirms that Green OA would provide a cost-effective route to improving access, with relatively high BCRs attributed to our central case in which much of the costs are treated as sunk. If we take Green solely to provide additional access to those who do not already have subscribed or licensed access, then it offers a cost-effective approach: at least as good as that offered by Gold if APCs are circa $£ 2,000$ or higher.

Unlike Gold, however, the Green scenario does not offer a route to cost savings for academic institutions, but instead involves increased annual costs, except in circumstances that give rise to other significant concerns. For if 
Green were also to replace some existing access and become (if only partly) a route to journal cancellation, there could of course be savings, but the scenario may not then be self-sustaining.

This suggests that it would be logical for policy to promote Green deposits since the repositories are already built and it would make sense to encourage their use - as a way of expanding access, so long as that is not at the expense of the other routes to access (in other words, with embargoes set at levels that do not damage subscriptions as the volume of deposits rises). The issue is of course obviated if publishing were to move to a Gold model.

\subsection{Licence Extension}

A national licence for UK universities would provide a BCR greater than one but lower than those for all the other scenarios. It has the disadvantage that it requires both initial one-off negotiating and other costs, and substantial continuing increased cash costs. It also faces significant issues relating to cost allocation between universities.

Such difficulties might be mitigated given the current weight being placed on shared services, or if a top-slicing solution is deemed to be politically feasible, particularly if there were other attractive features in the deal. Any comprehensive national arrangement would, however, be contrary to current competitive practice between universities, at a time when such competition is increasing.

On balance, therefore, it seems unlikely that a licence for all UK universities will be a priority at a time of public sector cuts. There may, however, be scope for new consortium licences based around regional blocs in which the primary negotiating focus of the institutions will be cost saving but will secondarily lead to some increased access.

\subsection{Transactional}

Similar considerations also apply to the Transactional scenario. Although there may be scope to increase access via improved service at lower prices, we lack the evidence to say with confidence that this is indeed the case, or if it is, whether it can be achieved in an economically sustainable way. Even with what we believe to be optimistic assumptions about the expansion of transac- 
tional volumes, the potential for increased access by this route is small. And the scenario does not appear to be amenable to public policy intervention, being more a matter of entrepreneurial activity and market forces.

\section{Fostering Change to Increase Access: Public Policy Implications}

We therefore believe that the messages for public policy that arise from our modelling and analysis are:

1. The Delayed scenario offers increases in access at closest to a zero cost. But it depends on voluntary action by publishers, and it is not directly amenable to policy influence by others (unless publishers were to adopt it as a potential defensive response to Green, something for which we see no evidence at present). Moreover, it would probably involve embargoes longer than funders such as the Wellcome Trust currently require; it could preclude aggregation of articles in subject repositories; and publishers would face risks that the current publishing system would be undermined by subscription cancellations. In our view, therefore, while there is no harm in policymakers encouraging it as a low-cost and arguably lower-risk ${ }^{17}$ way of expanding access, it is unlikely in practice to provide significant changes in access.

2. The Transactional scenario has some potential to address access gaps, and it could be complementary to other scenarios, or to the subscription model, provided it did not cannibalise subscriptions. It seems unlikely, however, that it would of itself lead to a substantial increase in access. Moreover, it is not particularly amenable to policy intervention, and the demand for transactional access would presumably fall as open access expands.

3. All the scenarios that are directly amenable to policy intervention by Government, universities and funders (Green, Gold, and Licence extension) are capable of achieving benefits to the UK greater than their costs. However, each has significant upfront costs of different kinds.

4. Of these options, the Licence extension option is the least attractive from a public policy perspective. Although the level of the BCR 
depends significantly on the premium that publishers actually charge for increased access, the combination of significant upfront and continuing cash costs (for universities in particular) and the difficulties of transition (including the allocation of costs) make the option relatively unattractive. These arguments are strengthened in the current difficult fiscal environment.

5. The two open access routes offer the greatest potential to public policy-makers in promoting access. Both have positive, and potentially high, BCRs.

6. The Green scenario could provide increases in access comparable to or greater than other scenarios, and since the infrastructure for Green has largely already been built, increasing access by this route is especially cost-effective. These gains, however, come with increased risks to the scholarly publishing system in the form of potential subscription cancellations, and thus the risk that the scenario is not selfsustaining.

7. The Gold route is preferable in the long-run, given (i) its underlying sustainability; (ii) the advantages of the author-side business model in terms of improved transparency and lower barriers to market entry, which point to improved economic efficiency; and (iii) (depending on the level of the APC) its potential to achieve both higher BCRs and lower net costs for the UK in general and for its universities in particular.

8. Set against those considerations, the scale of the costs and the benefits depends on the future level of APCs, which it may be hard for policy-makers to influence; and there are higher transition costs in the transition to Gold compared with Green.

9. Taking all these factors into account, our view is that the prudent stance for public policy-makers is:

- to encourage the use of existing Green infrastructure (whose costs are largely sunk); but to be cautious about pushing for reductions in embargo periods to the point where the sustainability of the underlying publishing model is put at risk.

- in parallel, to work to facilitate a transition to Gold OA (in specific disciplines such as the biosciences initially) provided that (i) the average level of APCs remains at or below circa $£ 2,000$; (ii) the proportion of articles funded through APCs in the UK 
moves broadly in line with global rates; and (iii) mechanisms are in place to ensure that total payments from UK universities and their funders do not rise as a consequence of this transition.

\section{Notes}

${ }^{1}$ Activities, costs and funding flows in the scholarly communications system in the UK (RIN 2008), available at http://www.rin.ac.uk/system/files/attachments/Activitescosts-flows-report.pdf.

${ }^{2}$ Houghton et al., Economic Implications of Alternative Scholarly Publishing Models (JISC, 2009), available at http://ie-repository.jisc.ac.uk/278/3/EI-ASPM

Report.pdf.

${ }^{3}$ The report of a study on the barriers to a move to e-only provision of scholarly journals in the UK - E-only scholarly journals: overcoming the barriers (RIN, 2010) — is available at http://www.rin.ac.uk/system/files/attachments/E-only report for screen 0.pdf. The report of a study on gaps and barriers to access, priorities in seeking to fill gaps, and actions that might be taken to that end will be published in the summer of 2011.

${ }^{4}$ Michael Jubb and Ellen Collins (RIN), Fred Friend and Neil Jacobs (JISC), Debby Shorley (RLUK), Graham Taylor (PRC) and Robert Kiley (Wellcome Trust).

${ }^{5}$ Heading for the open road: costs and benefits of transitions in scholarly communications (RIN, JISC, PRC, RLUK and Wellcome Trust, 2011), available at http:/ / www.rin. ac.uk/system/files/attachments/Dynamics of transition for screen 0.pdf.

${ }^{6}$ It is important to note that the modelling and analysis relates only to peer-reviewed journal articles as the primary means of scholarly communication. In order to simplify the analysis, we have intentionally excluded both monographs and conference publications.

${ }^{7}$ The steady state costs, changes in access and benefits have been estimated using a modified version of a model developed previously by CEPA for the report referred to in footnote 1 . Transition costs have been estimated separately and include both institutional transaction costs ('one-off' costs); and any 'ongoing' annual costs associated with system-wide transition (not captured in the 2008 CEPA model).

${ }^{8}$ Continuing annual costs include changes in (i) net costs incurred in supporting publication, distribution and access (i.e. 'steady state' costs); and (ii) the continuing annual costs associated with transition.

${ }^{9}$ This number is confirmed by our own estimates and given further validation by the average APC of $\$ 2,367$ paid for 440 Wellcome Trust-funded articles published in the 
last quarter of 2010. The Wellcome Trust articles were published in journals with a wide range of APCs, up to and including $\$ 5,000$ for Cell Press; the median was $\$ 2,250$ and the mode $\$ 3,000$.

${ }^{10}$ We show that the central-case cost of $£ 2,572$ per article would only have to be reduced by $17 \%$ for academic institutions to show a net zero cash cost.

${ }^{11}$ The Green 'Zero' case, which includes these sunk costs, is the most expensive for academic institutions, and also for other users

${ }^{12}$ Houghton et al., op. cit. note 2.

${ }^{13}$ The volatility of the BCR in the lower APC case reflects the relatively low level of costs in the central case. Small additions to these costs therefore have a disproportionate impact on the BCR.

${ }^{14}$ In economic terms this is expressed by saying that the price elasticity should be less than -1 .

${ }^{15}$ We assume a price elasticity of demand of -1.5 . This is a plausible level for other products with 'price elastic' demand. Such goods are typically those that are not necessities and make up a relatively small proportion of income

16 The costs of purchasing 300,000 articles at $\$ 10$ is approximately $£ 3.0 \mathrm{~m}$ compared with $£ 1.7 \mathrm{~m}$ for 58,000 articles at $\$ 30$, giving an additional cost to users of around $£ 1.3 \mathrm{~m}$.

${ }^{17}$ Since publishers would retain control and could take action. 